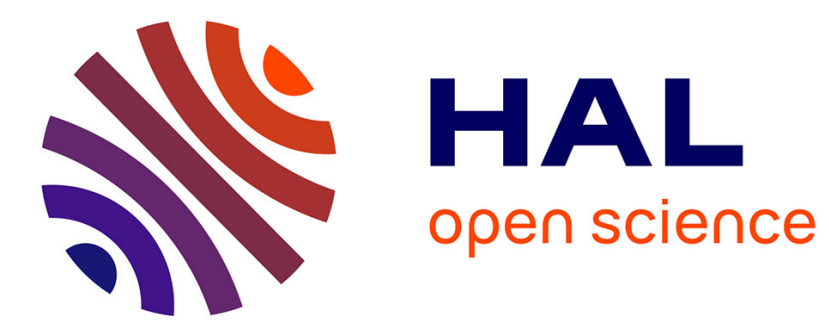

\title{
When Is It OK to Call Someone a Jerk? An Experimental Investigation of Expressives
} Bianca Cepollaro, Filippo Domaneschi, Isidora Stojanovic

\section{To cite this version:}

Bianca Cepollaro, Filippo Domaneschi, Isidora Stojanovic. When Is It OK to Call Someone a Jerk? An Experimental Investigation of Expressives. Synthese, 2021, 10.1007/s11229-020-02633-z . hal02522705

\section{HAL Id: hal-02522705 \\ https://hal.science/hal-02522705}

Submitted on 27 Mar 2020

HAL is a multi-disciplinary open access archive for the deposit and dissemination of scientific research documents, whether they are published or not. The documents may come from teaching and research institutions in France or abroad, or from public or private research centers.
L'archive ouverte pluridisciplinaire HAL, est destinée au dépôt et à la diffusion de documents scientifiques de niveau recherche, publiés ou non, émanant des établissements d'enseignement et de recherche français ou étrangers, des laboratoires publics ou privés. 


\title{
When Is It OK to Call Someone a Jerk?
}

\author{
An experimental investigation of expressives
}

\author{
Bianca Cepollaro, Filippo Domaneschi, Isidora Stojanovic ${ }^{1}$ \\ forthcoming in Synthese \\ (prepublication draft) \\ to quote, please refer to https://doi.org/10.1007/s11229-020-02633-Z
}

\begin{abstract}
We present two experimental studies on the Italian expressive 'stronzo' (English 'jerk'). The first study tests whether, and to which extent, the acceptability of using an expressive is sensitive to the information available in the context. The study looks both at referential uses of expressives (as in the complex demonstrative 'that jerk Marco') and predicative uses of expressives (as in 'Marco is a jerk'). The results show that expressives are sensitive to contextual information to a much higher degree than the non-expressive control items (such as 'Piedmontese') in their referential use, but also, albeit to a lesser degree, in their predicative use. The second study tests whether the lower acceptability of expressives in their predicative use may be simply due to saying something negative about someone. A comparison between expressives, such as 'jerk', and non-expressive negative terms, such as 'nasty' or 'unbearable', suggests that it is the expressive nature of these terms, rather than the mere negative valence, that affects acceptability. Our studies present a major challenge to the existing accounts of expressives, and raise several theoretical issues that still call for an answer.
\end{abstract}

Keywords: pejoratives; expressives; projective content; contextual felicity

\section{Introduction}

The twenty-first century has witnessed a growing interest in the study of what is broadly called expressive meaning. Pejorative and derogatory terms are paradigmatic examples of expressive meaning: by using them, the speakers express their negative attitudes, such as hatred or contempt, towards the persons designated by the locutions at stake. A large amount of this recent literature has focused on slurs: terms that derogate their targets in virtue of their race, ethnicity, gender, sexual orientation or religion. ${ }^{2}$ Much less interest has been devoted to particularistic insults (to use the terminology from Saka 2007); that is, expressives such as 'jerk' or 'bastard', which target individuals alone, regardless of any social group to which

\footnotetext{
1 The authors have equally contributed to this work; their names are listed in alphabetic order. We would like to thank two anonymous reviewers for Synthese, several anonymous reviewers for SALT and Sinn undBedeutung for constructive comments on previous drafts, Judith Tonhauser and Neftalí Villanueva for stimulating discussion, Simona di Paola for support in the statistical analysis, the audiences at the workshop Language and Power (Barcelona, May 2018), PhiloLab Summer School (Granada, September 2018), XPrag in Edinburg (June 2019), SEFA in Valencia (November 2019) for their insights, comments and suggestions. Bianca Cepollaro also gratefully acknowledges the support of the National Grant G45J18000030001 (University of Milan) and the PRIN Project The Mark of Mental (MOM) 2017P9E9N, and Isidora Stojanovic, of the Project ANR-17EURE-0017 FrontCog.

2 See i.a. Schlenker (2007), Hom (2008), McCready (2010), Langton et al. (2012), Anderson and Lepore (2013a, 2013b), Camp (2013, 2018) Jeshion (2013, 2018), Cepollaro and Stojanovic (2016), Bolinger (2017), Nunberg (2018), Cepollaro (forthcoming).
} 
they may belong. ${ }^{3}$ The driving motivation of this work is to understand how expressives such as 'jerk' or 'bastard' compare to non-expressives with respect to the constraints that their use imposes on the context. ${ }^{4}$

In section 2, we consider three analyses of expressives as triggers of projective content (2.1) and observe that they offer similar predictions concerning the constraints associated with expressives: we shall take those three analyses to constitute what we call the mainstream view (2.2). In section 3, we present two alternative hypotheses concerning the contextual constraints imposed by expressives such 'that jerk', and we extend our investigation to 'jerk' in the predicative position. In section 4 and section 5, we present and discuss our studies.

\section{Background}

\subsection{Expressives as triggers of projective content}

In linguistic and philosophical literature, expressives such as 'that bastard', 'that jerk' etc. taken to be associated with a certain negative content that survives embedding: whatever expressive content (1) conveys, it is equally conveyed in (2)-(5):

(1) That bastard Marco is talking.

(2) It's not the case that that bastard Marco is talking.

(3) Is that bastard Marco talking?

(4) If that bastard Marco is talking, you should listen.

(5) It may be the case that that bastard Marco is talking.

In this section, we consider three theories of expressives as triggers of projective content: (i) Potts (2005); (ii) Schlenker (2007); and (iii) Tonhauser, Beaver, Roberts and Simons (2013). All three approaches take the expressive content of locutions such as 'that bastard' to reflect the speaker's feelings or attitudes concerning the target of the expressive. ${ }^{5}$

For Potts, expressives such as 'that jerk' carry a conventional implicature, an additional content that is separated from the descriptive compositional meaning. Potts characterizes these conventional implicatures as speaker-oriented and attitudinal: they concern the mental state of the speaker of the utterance. If Bea says 'That jerk Marco has arrived', bystanders come to know that Bea has a low opinion of Marco and this content is independent from the descriptive content, namely that Marco has arrived.

For Schlenker, expressives such as 'that jerk' trigger a presupposition that is indexical (i.e.

\footnotetext{
${ }^{3}$ Slurs and expressives do not necessarily split neatly into two separate classes. The term 'bitch' is a case at point: it is sometimes seen as an expressive, that is, as a female equivalent of 'bastard', but at other times it is considered to be a slur that derogates not only the individual for whom it is used, but all women as such (see Ashwell 2016: her point concerns whether or not slurs have a neutral counterpart in general, but we can take her arguments and examples to show a borderline case between slurs and particularistic insults).

4 Throughout the paper, we will be simply using the term 'expressive' for pejorative epithets such as 'jerk' or 'bastard', leaving aside other expressions that are considered to belong among expressive, such as the modifiers 'fucking' and 'damn', interjections such as 'awesome', and the like.

5 There are certain constructions, such as free indirect discourse, in which the expressive content is seen as reflecting not the speaker's (or the narrator's) feelings and attitudes, but rather, those of some salient protagonist whose speech or thought are being reported. The use of expressives in such constructions falls beyond the scope of the present paper. For discussion, see i.a. Amaral et al. (2007) Schlenker (2007), Potts (2007), Harris and Potts (2009), Harris (2012), Kaiser (2015).
} 
evaluated with respect to the context of utterance) and attitudinal (i.e. it concerns the mental state of the speaker). Presupposition and conventional implicature are, in Abbott's words, "close neighbor[s] in the linguistic literature" (Abbott 2006: 2) and there is an ongoing debate about how to distinguish and characterize them. One trait that distinguishes presupposition from conventional implicature is their projective pattern. Since conventional implicatures are syntactically independent, they project under any embedding; presuppositions, on the other hand, can be locally accommodated in certain contexts. In order to account for the hyperprojectivity of expressions such as 'that jerk', Schlenker needs the presuppositions at stake to be not only attitudinal, but also indexical, i.e. always about the mental state of the speaker. ${ }^{6}$

Judith Tonhauser, David Beaver, Craige Roberts and Mandy Simons proposed a series of novel diagnostics in order to distinguish among types of projective content, hitherto thought of in terms of presuppositions and conventional implicatures. The heterogeneity of projective content has been widely recognized (Chierchia \& McConnell-Ginet 1990, Simons 2001, Abusch 2002, 2010, Potts 2005, 2007, Abbott 2006, Simons et. al 2011), but theirs is arguably the first attempt at gaining a more systematic classification of these heterogeneous categories. They distinguish four classes of triggers along two properties, called Strong Contextual Felicity Constraint (SCFC) and Obligatory Local Effect (OLE). According to Tonhauser et al. (2013), activators of conventional implicatures à la Potts (2005), including expressives, belong to 'class B' of their taxonomy, that is, to the class of items that have neither SCFC nor OLE. In this paper, we are only interested in SCFC.

In the next section, we will look at the predictions made by the three approaches regarding the constraints associated with expressives. However, before we proceed, let us briefly tackle the question of how the class of expressives is to be delineated in the first place. We follow the literature in taking expressions such as '(that) jerk' or '(that) bastard' to be paradigmatic examples of expressives. But this leaves open the possibility that there may not be a clear-cut difference between these and other expressions that have a descriptive rather than expressive meaning. For instance, Lasersohn $(2007,2017)$ takes expressions like 'jerk' to be essentially descriptive, and treats them as predicates of personal taste (PPTs), such as 'delicious' or 'fun'. Conversely, Potts (2005) appears to include the latter among expressives, since he uses 'lovely' as one of his main examples of expressives. Pace Lasersohn and Potts, we take it to be highly problematic to assimilate expressives to PPTs or vice versa. The two classes appear to have different semantic functions, as Berškytė and Stevens (2019) have convincingly argued in relation to the phenomena of perspective sensitivity and projection failure in the two cases. Nevertheless, we are also sympathetic to the thought that expressive meaning may constitute a broader phenomenon, not limited to the use of expressives like '(that) jerk' and locutions like 'fuck' or 'damn'. Recently, Soria Ruiz and Stojanovic (2019) have suggested that virtually any expression with descriptive meaning, and PPTs in particular, can be used with an expressive meaning, and have proposed linguistic criteria that distinguish between the descriptive and the expressive use. For the purposes of the present paper, however, let us focus on paradigmatic expressives and leave it open how precisely these are distinguished from the rest.

\subsection{Predictions about contextual constraints: the mainstream view} ${ }^{6}$ Schlenker (2007) allows such indexical presuppositions to shift under certain circumstances, so that in indirect
reports, the speaker to whom the indexical is attached can be either the reporter or the reportee. 
As we mentioned above, all three approaches agree on analyzing the projective content associated with expressives such as 'that jerk' as conveying the information that the speaker has a negative attitude toward the referent. For Potts (2007: 185), when Tom utters 'that jerk Jerry', bystanders come to know that Tom feels negatively about Jerry. Tom has a privileged access to his own feelings: Potts (2005) takes this to mean that interlocutors cannot dispute utterances like 'That jerk Conner got promoted' in the same way they dispute factual utterances like 'Conner got promoted'. He considers the following dialogue and then comments:
a. Anne: That bastard Conner got promoted
b. Kyle: Conner is not a bastard
(...)
We analyze epithets and other expressives as expressing properties of speakers' emotional states. In this way, we ensure that outright denials of their content by a hearer will make little sense. If we try to interpret Kyle's reply (...) as a challenge to Anne's view of Conner, then the scenario becomes as far-fetched as one in which Kyle seriously challenges that Anne has a certain opinion or is in a state of pain. In all these cases, Kyle must deny an event that Anne has privileged access to. (Potts 2005: 157-158)

For Potts, conventional implicatures typically provide information that is not already part of the common ground when they are uttered. ${ }^{7}$ Since (i) the information conveyed by expressives is typically new, (ii) it concerns the speaker's feelings and (iii) the speaker is the main authority in that matter, expressives such as 'that jerk' do not impose any special constraints on the context. In other words, Potts' theory predicts that expressives do not require any particular contextual information for their utterances to be felicitous.

Things are slightly different for Schlenker. Consider (6), uttered by Tom:

(6) That bastard Jerry has arrived.

In Schlenker's view, (6) has failure conditions. It suffers from presuppositional failure iff it is not the case that the agent of context $c$ (Tom) has a low opinion of Jerry in the world of $c$ (see Schlenker 2007: 238). In other words, for 'that bastard Jerry has arrived' to be felicitous, the presupposed content - that Tom has a low opinion of Jerry - must be true. A further question is whether this presupposition also needs to be entailed by the common ground, as is normally the case for presupposition. Potts emphasizes that the projective content of expressives can be new information, a feature that leads him to prefer a conventional implicature analysis over a presuppositional one, given that presuppositions typically impose backgrounding conditions while conventional implicatures do not. However, Schlenker's proposal can account for the cases where the expressive content of locutions such as 'that bastard' or 'that 'jerk' is not part of the common ground in at least two ways. One way is to rely on the mechanism of accommodation (Lewis 1979, Stalnaker 2002), given the authority that each speaker has on their own mental states:

We could postulate that a presupposition about the speaker's attitudes is particularly easy to accommodate because the addressee takes the speaker to be an authority on his own mental states

\footnotetext{
7 The relevant notion of common ground comes from Stalnaker, as succinctly captured in this quote: "It is common ground that $\varphi$ in a group if all members accept (for the purpose of the conversation) that $\varphi$, and all believe that all accept that $\varphi$, and all believe that all believe that all accept that $\varphi$, etc." (Stalnaker 2002: 716).
} 
(following Lewis 1979, we take accommodation to be a repair strategy by which the addressee accepts to modify his beliefs in order to prevent a sentence from resulting in a presupposition failure) (Schlenker 2007: 241).

Schlenker proposes a second explanation, which he favors, involving no accommodation: "(...) we believe that there is a more principled way to explain these facts: without any kind of 'repair', there are cases in which presuppositions are systematically informative" (Schlenker 2007: 241) Presuppositions which are indexical and attitudinal are taken to be "self-fulfilling": if the speaker is in the required state of mind (i.e. has a low opinion of the target), once s/he utters the expressive 'that jerk', it automatically becomes common ground that $\mathrm{s} /$ he has a low opinion of the target.

Both Potts and Schlenker share the idea that expressives do not impose any strong constraints on the context, in the sense that when Tom utters 'that bastard Jerry', bystanders come to know that Tom feels negatively about Jerry; there is no need for any backgrounded information.

In a similar spirit, Tonhauser et al. (2013) analyze expressives as lacking a Strong Contextual Felicity Constraint, which roughly means that expressives are triggers that do not need the common ground to already include information about how the speaker feels toward the referent in order for their utterance to be felicitous. ${ }^{8}$

In order to present Tonhauser et al.'s SCFC, we need to introduce the notion of m-neutral and m-positive contexts. Take (7):

(7) Jesse has stopped doing yoga.

(7) features the trigger 'stopped', which is associated with the projective content $m$ that Jesse used to do yoga. An m-positive context is a context where it is common ground that Jesse used to do yoga. On the other hand, an m-neutral context is one that implies neither $m$ nor $\neg m$, hence one where it is not common ground whether Jesse used to do yoga or not. Note that a context where everyone knows that Jesse has never done yoga would not count as neutral because it implies $\neg m$; a context is neutral only if it implies neither $m$ nor $\neg m$. Tonhauser et al. (2013: 76) define SCFC as follows:

(SCFC) "If utterance of trigger $t$ of projective content $m$ is acceptable only in an $m$-positive context, then $t$ imposes a strong contextual felicity constraint with respect to $m$ ",

To test SCFC, Tonhauser et al. (2013) propose the following diagnostic:

\footnotetext{
8 Tonhauser et al. do not employ the notion of accommodation, but they acknowledge a certain link between the Strong Contextual Felicity Constraint and the ease with which a presupposition can be accommodated: "These empirical observations about English presupposition triggers are traditionally rendered consistent with the assumption that the English expressions impose constraints on contexts (e.g. Heim 1983, van der Sandt 1992, Geurts 1999, Schlenker 2009) by assuming the availability of ACCOMMODATION (Lewis 1979, building on Stalnaker 1974). Accommodation is a process whereby the interpreter 'updates' her view of the context to render it suitable for the utterance of the relevant trigger. From this theoretical perspective, those (English and Guaraní) triggers that test positive on the diagnostic for the strong contextual felicity constraint are subject to a particularly strong constraint on context that cannot be satisfied by accommodation. Those that test negative on the diagnostic might either be subject to a weak constraint that allows for satisfaction via accommodation, or might not be subject to a constraint at all. (See Simons et al. 2011 for arguments against the accommodation view)" Tonhauser (2013: 80).
} 
"Let $\mathrm{S}$ be an atomic sentence that contains trigger $t$ of projective content $m$.

(i)If uttering $\mathrm{S}$ is acceptable in an $m$-neutral context, then trigger $t$ does not impose a strong contextual felicity constraint with respect to $m$;

(ii)If uttering $\mathrm{S}$ is unacceptable in an $m$-neutral context and acceptable in a minimally different $m$-positive context, then trigger $t$ imposes a strong contextual felicity constraint with respect to $m$ " (Ibidem).

In our study, we will keep this idea of comparing the acceptability of utterances of sentences containing expressives, presented in m-neutral vs. m-positive contexts, in order to determine whether the items at stake impose any contextual constraints. We call "neutral" those contexts in which it is not common ground whether the subject of the expressive sentence is (or should be) looked upon negatively (this roughly corresponds to Tonhauser et al.'s "m-neutral" contexts); we call "satisfying" those contexts where it is common ground that the subject of the expressive sentence is (or should be) looked upon negatively (this roughly corresponds to Tonhauser's "m-positive" contexts). If expressives impose a constraint along the lines of Tonhauser et al. (2013)'s SFCF, then we should expect the acceptability rates of utterances containing expressives to be significantly lower in the neutral contexts than in satisfying contexts, in comparison to controllers.

This brief overview shows that most existing accounts of expressives as triggers of projective content predict that locutions such as 'that bastard', 'that jerk' etc. do not impose any contextual constraints (in the sense of backgrounded information). We will call this the mainstream view. In the next section, we will put forward two other alternative hypotheses and broaden the study of expressives from utterances such as 'that jerk Jerry has arrived' to 'Jerry is a jerk'.

\section{Three hypotheses about 'that jerk' and '(a) jerk'}

Our main aim in this paper is to investigate on empirical grounds the hypothesis on which the three approaches, namely Potts', Schlenker's and Tonhauser et al.'s, appear to agree: (H1) expressives do not impose any special contextual constraints, and their use does not require that the associated projective content should be entailed by the context. There are, however, two alternative hypotheses that we want to examine: (H2) expressives do impose certain contextual constraints, and the felicity of their use depends on the contextual availability of the associated projective content; (H3) since expressives are taboo terms that are never deemed felicitous, whether the projective content associated with expressives is or is not part of the common ground is irrelevant. ${ }^{9}$

When investigating the properties of expressives such as 'that jerk', a further question arises: if $\mathrm{H} 2$ is correct and 'that jerk' turns out to impose contextual constraints in the way that standard presuppositions do, is it because of (i) the demonstrative construction 'that' -

\footnotetext{
9 Note that H3 is not strictly speaking incompatible with $\mathrm{H} 1$ and $\mathrm{H} 2$ : a H3-supporter could hold that because expressives are taboo words, they are always infelicitous, so by investigating how acceptable their use is, one cannot investigate whether they impose contextual constraints. H3 can be seen as an extension of Anderson and Lepore (2013a, 2013b)'s theory of slurs to other expressives.
} 
which would mean that the mechanism at stake has little to do with expressives ${ }^{10}-$, or (ii) the occurrence of the expressive 'jerk', or (iii) both the 'that-' construction and the occurrence of the expressive? This question has been largely neglected in the literature. In order to start addressing this issue, we are broadening the study of expressives by extending the scope of interest to their predicative uses.

In our studies, we will be looking at two types of sentences:

(REF) That jerk N VP. (e.g. That jerk Jerry has arrived.)

(PRED) $\mathrm{N}$ is a jerk. (e.g. Jerry is a jerk.)

(REF) represents the sentence-type that has been paradigmatically discussed in the literature on expressives (Kaplan 1999, Potts 2005, Schlenker 2007, Macià 2002, 2011, Tonhauser et al. 2013), while (PRED)-type sentences have not been much discussed. Let us now formulate the three hypotheses introduced above for the referential and predicative uses of expressives, in terms of the notions of neutral and satisfying contexts that we introduced in section 2 :

$\left(\mathrm{H} 1_{\mathrm{REF}}\right)(\mathrm{REF})$ is acceptable in satisfying as well as neutral contexts.

$\left(\mathrm{H} 2_{\mathrm{REF}}\right)(\mathrm{REF})$ is acceptable in satisfying but not in neutral contexts.

$\left(\mathrm{H} 3_{\mathrm{REF}}\right)(\mathrm{REF})$ is never acceptable.

Similarly:

(H1 PRED) (PRED) is acceptable in satisfying as well as neutral contexts.

(H2PRED) (PRED) is acceptable in satisfying but not in neutral contexts.

(H3PRED) (PRED) is never acceptable.

Before we present our studies, two clarifications are in order. The first one concerns the very notion of acceptability, and the second the expressive content associated with 'jerk' and 'that jerk'.

First, acceptability is arguably a gradable notion. Both $\mathrm{H} 2$ and $\mathrm{H} 3$ predict that expressives are unacceptable (for H2, they are unacceptable in neutral contexts; for H3, they are always unacceptable), but this need not mean that they are completely unacceptable. Rather, we should understand these hypotheses as saying that expressives are (at least in some contexts) systematically and significantly less acceptable than non-expressives, such as our controllers. Our studies will therefore examine the acceptability of expressives in comparison to that of non-expressives.

Second, many scholars (Potts, Schlenker, Tonhauser et al.) hold that the expressive content of 'that jerk' concerns the feelings and attitudes of the speaker regarding the target. An

10 As a matter of fact, when scholars talk about 'jerk', they are actually talking about 'that jerk'. This passage from Potts is representative of this tendency: "In 'That jerk Ed skipped work last week (...)' The expressive contribution of jerk is not interpreted in the scope of the past tense of the first sentence's main clause" Potts (2005: 159). What Potts is actually talking about is the that jerk, not jerk. 
alternative option is that the expressive content is directly about the target: for instance, that the target is a bad person and ought to be held in low opinion. In our studies, we have chosen the second option: a satisfying context for 'jerk' and 'that jerk' will be one where it is common ground either that the target ought to be held in low opinion, or that people in general have a negative attitude about the target. While the first option may have stayed closer to testing the standard view, we have gone for the second option because it is more inclusive. That is to say, any context in which the target ought to be held in low opinion will (defeasibly) be such that the speaker will have a negative attitude about the target. However, let us acknowledge that the acceptability of expressives may turn out to vary according to the specific choice of expressive content, and, in particular, that using the expression 'jerk' to refer to someone may be more acceptable in a context in which the person at stake deserves to be held in low opinion, than in one in which the speaker, for whatever reason, has negative feelings about him or her. ${ }^{11}$

\section{Study 1}

In order to test the different theoretical hypotheses regarding the acceptability of expressives, we ran a study on the Italian 'stronzo' (the equivalent of English 'jerk'). The study compares the behavior of this expressive and various non-expressive predicates in satisfying and neutral contexts. In a nutshell, the results of our study show that the availability of the relevant contextual information (viz. that someone deserves to be held in low opinion in the case of expressives, or that someone has the property encoded in the lexical meaning in the case of non-expressives) has an impact on the acceptability of expressives to a much greater extent than in the case of non-expressives.

\subsection{Methods}

Participants

90 participants took part to the study $[\mathrm{MA}=23.59 ; \mathrm{SD}=6.83 ; 59 \mathrm{f} ; 31 \mathrm{~m}]$. Participants were all native Italian speakers. The experiment was administered online. Informed consent was obtained from every participant.

\section{Stimuli}

We created eight written vignettes in Italian (randomly presented). Each vignette was a story composed of a context scenario consisting of three or four sentences, followed by a target sentence. The context scenario describes a circumstance in which two people are having a conversation about a third person. The target sentence is an utterance made by one of the two interlocutors about the third person. Three independent variables were manipulated in the stimuli: two on the target sentences, one on the scenarios.

As for the target sentences, they included either the expressive 'stronzo' ('jerk') (EXP) or a controller sentence where the expressive was replaced by a non-expressive term such as 'piemontese' ('Piedmontese') (CON). These expressions (EXP or CON) occurred in the target sentence either within a complex demonstrative (e.g. 'Quella stronza/piemontese di Bea ha finito di lavorare, tr. 'That jerk/Piedmontese Bea has taken off work) or else in the predicate position (e.g. 'Bea è stronza/piemontese', tr. 'Bea is a jerk/Piedmontese'). This

11 We are grateful to an anonymous reviewer for pressing this point. We also plan to run a follow-up study that will distinguish between the two contexts, and compare the respective rates of acceptability. 
manipulation resulted in four possible types of target sentences for each story: Ref-EXP, RefCON, Pred-EXP, Pred-CON.

As for the context scenarios, a further manipulation was introduced: each vignette could have a satisfying context or a neutral context. The satisfying condition was identical to the neutral condition, except for one detail: the former had an additional sentence that made available the information associated with the lexical item featuring in the target sentence, either the expressive 'stronzo' (EXP) or the controller (CON). So each of the four versions for each story could occur in a satisfying or a neutral condition (NEU vs. SAT).

In order to illustrate the main characteristics of the stimuli, here we show the four versions (Pred-EXP, Pred-CON, Ref-EXP, Ref-CON) of one of the stories, each of which can come in the satisfying condition or in the neutral condition (NEU vs. SAT), diverging in whether they include the sentence in angle brackets. ${ }^{12}$ For each version, the target sentence is in italics.

1a. (SAT_Pred-EXP) Pietro e Marta sono camerieri in un ristorante. Bea fa l'aiuto cuoco. $<$ È poco amata dai colleghi perché è scortese con tutti.> Quando Bea finisce il turno, Marta dice a Pietro: Bea è stronza.

[Pietro and Marta are waiters in a restaurant. Bea is the assistant chef. <Her colleagues do not like her much because she is rude to everyone. $>$ When Bea finishes her shift, Marta tells Pietro: Bea is a jerk]

1b. (NEU_Pred-EXP) Pietro e Marta sono camerieri in un ristorante. Bea fa l'aiuto cuoco. Quando Bea finisce il turno, Marta dice a Pietro: Bea è stronza.

[Pietro and Marta are waiters in a restaurant. Bea is the assistant chef. When Bea finishes her shift, Marta tells Pietro: Bea is a jerk]

2a. (SAT Ref-EXP) Pietro e Marta sono camerieri in un ristorante. Bea fa l'aiuto cuoco. $<$ È poco amata dai colleghi perché è scortese con tutti.> Quando Bea finisce il turno, Marta dice a Pietro: Quella stronza di Bea ha finito di lavorare.

[Pietro and Marta are waiters in a restaurant. Bea is the assistant chef. <Her colleagues do not like her much because she is rude to everyone. $>$ When Bea finishes her shift, Marta tells Pietro: That jerk Bea has finished.]

2b. (NEU Ref-EXP) Pietro e Marta sono camerieri in un ristorante. Bea fa l'aiuto cuoco. Quando Bea finisce il turno, Marta dice a Pietro: Quella stronza di Bea ha finito di lavorare.

[Pietro and Marta are waiters in a restaurant. Bea is the assistant chef. When Bea finishes her shift, Marta tells Pietro: That jerk Bea has finished working.]

3a. (SAT_Pred-CON) Pietro e Marta sono camerieri in un ristorante. Bea fa l'aiuto cuoco. $<$ Bea è piemontese ed è esperta delle ricette tipiche>. Quando Bea finisce il turno, Marta dice a Pietro: Bea $\grave{e}$ piemontese.

[Pietro and Marta are waiters in a restaurant. Bea is the assistant chef. $<$ Bea is Piedmontese and she knows about the typical recipes.> When Bea finishes her shift, Marta tells Pietro: Bea is Piedmontese.]

3b. (NEU_Pred-CON) Pietro e Marta sono camerieri in un ristorante. Bea fa l'aiuto cuoco. Quando Bea finisce il turno, Marta dice a Pietro: Bea è piemontese.

[Pietro and Marta are waiters in a restaurant. Bea is the assistant chef. When Bea finishes her shift, Marta tells Pietro: Bea is Piedmontese.]

4a. (SAT_Ref-CON) Pietro e Marta sono camerieri in un ristorante. Bea fa l'aiuto cuoco. $<$ Bea è piemontese ed è esperta delle ricette tipiche>. Quando Bea finisce il turno, Marta dice a Pietro: Quella

12 As pointed out at the end of the previous section, it is a non-trivial question of what the expressive content associated with an expression like 'jerk' should be. In the following scenario, we have described a satisfying context by describing the target (Bea) as someone whom her colleagues do not like because she is rude to everyone. As an anonymous reviewer has rightly pointed out, this context entails that Bea is "a jerk" only modulo the assumption that her being rude to everyone, and hence disliked by everyone, makes her worthy of such a negative attitude. Nevertheless, we believe that our scenarios reflect as accurately as possible the differences that one would want to find between satisfying and non-satisfying contexts. (Note, furthermore, that stating explicitly in the scenario that Bea "is a jerk" was not a viable option.) 
piemontese di Bea ha finito di lavorare.

[Pietro and Marta are waiters in a restaurant. Bea is the assistant chef. $<$ Bea is Piedmontese and she knows about the typical recipes.> When Bea finishes her shift, Marta tells Pietro: That Piedmontese Bea has finished working.]

4b. (NEU Ref-CON) Pietro e Marta sono camerieri in un ristorante. Bea fa l'aiuto cuoco. Quando Bea finisce il turno, Marta dice a Pietro: Quella piemontese di Bea ha finito di lavorare.

[Pietro and Marta are waiters in a restaurant. Bea is the assistant chef. When Bea finishes her shift, Marta tells Pietro: That Piedmontese Bea has finished working.]

5. Fillers included the same material, except for the target sentence, which could be one of the following (for this particular story):

Bea è molto alta [Bea is very tall]; Da quanto conosci Bea? [How long have you known her?]; Tra poco stacchiamo anche noi! [We are finishing our shift too!]; Con la gente che c'è stasera chissà che incassi facciamo [With this crowd, imagine how much money we'll make tonight]; Almeno la cucina chiude a una certa ora! [At least the kitchen closes at some point]; Bea ha il giorno libero domani? [Does Bea have her day off tomorrow?]; Io non lo sapevo. [I didn't know it]; Non è la prima né l'ultima. [It is not the first or last one]; Cosa pensi sia successo? [What do you think happened?]; È proprio un peccato che capiti di lunedì [It's such a shame this happens on Monday]; Bea non impara mai [Bea never learns].

\section{Procedure}

The procedure consisted in reading the context scenarios. Participants were then asked to rate on a 5-point Likert scale (1 unacceptable; 5 completely acceptable) the degree of acceptability of a list of 12 sentences describing utterances of one of the two interlocutors about the third person of the story. The list contained 11 filler sentences plus the target sentence, presented in random order. The filler sentences contained grammatical/ ungrammatical and pragmatically consistent/inconsistent sentences.

In requiring participants to rate the 'acceptability' of the target sentences, we adopt the same question task as Tonhauser et al. (2013). The adoption of the notion of 'acceptability', with no further qualification, contributes to the ecology of the experimental task. It is true, however, that it leaves room for at least three interpretations. Target sentences might be rated as acceptable/unacceptable along three different parameters: grammaticality, social acceptability and contextual acceptability. Grammatical acceptability concerns the morphosyntactic correctness of the target sentence, while social acceptability concerns the appropriateness of an utterance of a target sentence with respect to the general principles of politeness. Neither of these notions of 'acceptability' is the one that we are aiming to capture. Instead, we are interested in assessing the contextual acceptability of target sentences, i.e. the degree to which an utterance is deemed felicitous in the absence of satisfying contextual information. Our manipulation targets that third interpretation of the notion of acceptability: any significant difference in average rates on the target sentences is expected to be the effect of the manipulation of our independent variable, i.e. the presence/absence of satisfying contextual information in the context scenario. ${ }^{13}$

\subsection{Results}

In analyzing the data, we investigated whether there were any differences in response combinations between (i) SAT vs NEU, (ii) Pred-EXP vs. Pred-CON and (iii) Ref-EXP vs. Ref-CON.

13 While our studies have been designed to test contextual acceptability, they do not completely rule out the possibility that certain participants may be tracking the notion of social acceptability after all. 
First, the two-sided Wilcoxon sum-rank test with Yates' continuity correction revealed that the responses in SAT_Pred-EXP differed significantly from the responses in NEU_Pred-EXP (W(1677); $\mathrm{p}<0.0001)$, with higher rates in SAT_Pred-EXP than in NEU_Pred-EXP; SAT_Pred-CON significantly differed from NEU_Pred-CON (W(3254); $<<0.01)$ with higher average rates in SAT; SAT_Ref-EXP significantly differed from NEU_Ref-EXP (W(1422.5); $\mathrm{p}<0.0001)$ with higher rates in SAT and, finally, SAT_Ref-CON differed significantly from NEU_Ref-CON (W(2417.5); $p<0.0001)$ with higher average rates again in SAT_Ref-CON see Fig. 1.

Second, two-sided Wilcoxon sum-rank test with Yates' continuity correction revealed that the responses in SAT_Pred-EXP differed significantly from NEU_Pred-CON (W(1707.5); $\mathrm{p}<$ 0.0001) with higher average rates again in NEU_Pred-CON; NEU_Pred-EXP differed significantly from SAT_Pred-CON (W(4901.5); $p<0.01)$ with higher average rates again in Pred-CON.

Thirdly, NEU_Ref-EXP differed significantly from NEU_Ref-CON (W(5523.5); $\mathrm{p}<$ $0.0001)$ with higher rates in NEU_Ref-CON. Interestingly, a significant difference was also observed between NEU_Pred-CON vs. NEU_Ref-CON (W(4926.5); $<<0.009$ ) with higher average rates in NEU_Pred-CON - see Fig. 2.

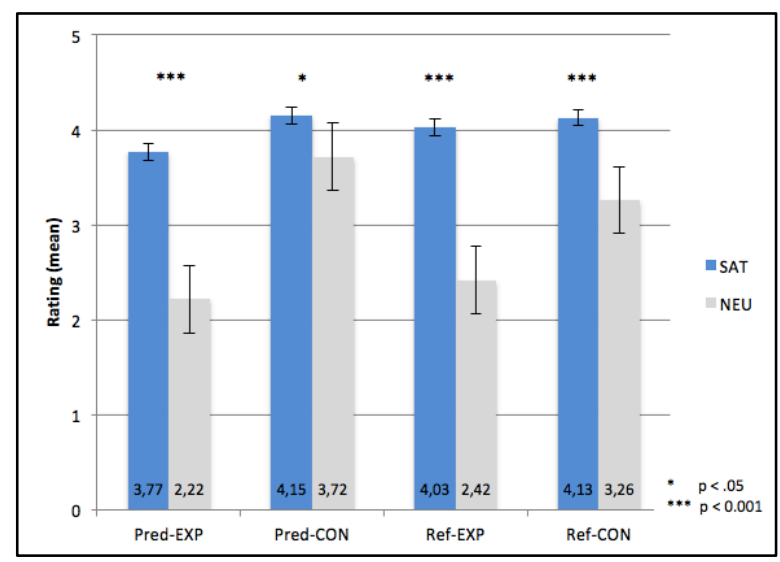

Fig 1 Mean rates to the four types of sentences ((i) expressive in predicative position Pred-EXP; (ii) controllers in predicative position Pred-CON; (iii) expressive in referential position Ref-EXP; (iv) controllers in referential position Ref-CON) in the two experimental conditions SAT vs. NEU.

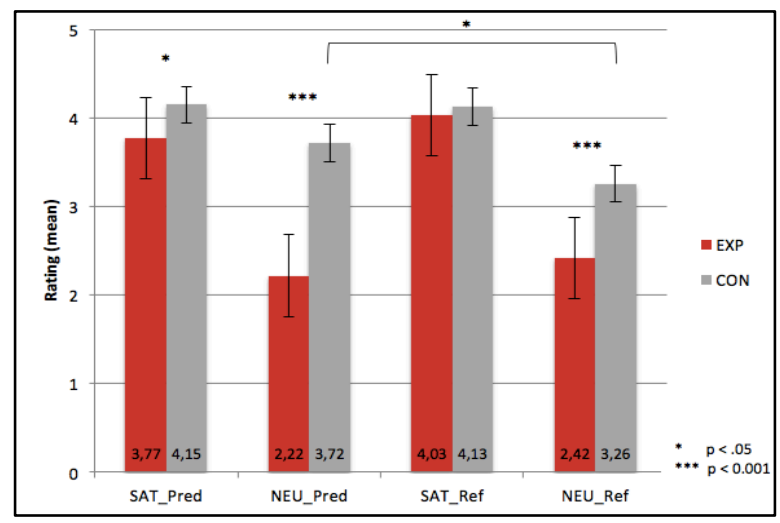


Fig 2 Mean rates to expressive vs. controllers in the predicative position in the two experimental condition (SAT_Pred and NEU_Pred) and in the referential position (SAT_Ref and NEU_Ref).

\subsection{Discussion}

In order to critically assess the results of this study, recall that the main aim of our work is to investigate on empirical grounds the acceptability of expressives in context. We are looking at three hypotheses. According to H1, a hypothesis widely agreed upon in the existing literature (Macià 2002, 2011, Potts 2005, Schlenker 2007, Tonhauser et al. 2013, i.a.), the use of expressives does not require that the associated projective content should be entailed by the context. According to H2, expressives do impose certain contextual constraints, and the felicity of their use depends on the contextual availability of their associated projective content. According to $\mathrm{H} 3$, whether the projective content associated with expressives is entailed by the context or not is irrelevant, as expressives are taboo terms that are never deemed acceptable.

To see how our results bear upon these three hypotheses, recall that acceptability is a gradable notion. Both $\mathrm{H} 2$ and $\mathrm{H} 3$ predict that expressives are unacceptable (for $\mathrm{H} 2$, they are unacceptable in neutral contexts; for H3, they are always unacceptable), but this does not necessarily mean a zero degree of acceptability; rather, these two hypotheses predict that expressives are (at least in certain contexts) systematically and significantly less acceptable than non-expressives such as the controller items that we tested.

The results of our study speak against $\mathrm{H} 1$ and $\mathrm{H} 3$, and in favor of $\mathrm{H} 2$. Let us start with $\mathrm{H} 3$ : we see that the utterances in which 'jerk' occurs, whether in a referential or in a predicative position, are perfectly acceptable in satisfying contexts. This result alone disconfirms H3.

Importantly, our results also speak against $\mathrm{H} 1$, the hypothesis shared by most views on expressives, and in favor of $\mathrm{H} 2$. We do not draw this conclusion from the mere observation that uses of 'stronzo' are less acceptable in neutral contexts than in satisfying contexts, as a similar effect can be found across the four conditions (Pred-EXP, Ref-EXP, Pred-CON and Ref-CON), albeit to different extents. What is crucial to our claim is that the extent to which the acceptability gets downgraded in neutral contexts in the case of expressives is much greater than in the case of non-expressive terms - see Fig. 2. In other words, in a context in which it is not known whether Bea is Piedmontese and a speaker refers to her as 'that Piedmontese Bea', participants tend to find what the speaker says significantly more acceptable than in a similar context in which a speaker refers to Bea as 'that jerk Bea' and it is not known whether Bea deserves to be held in low opinion, or whether the speaker holds her in such low opinion for whatever reason. Hence, even if the use of an expressive is not outright unacceptable in a neutral context, the fact that its acceptability gets downgraded in comparison with the controller sentences is what we take to be strong evidence that speaks against $\mathrm{H} 1$ and in favor of $\mathrm{H} 2$.

In addition to showing that expressives differ significantly from non-expressives when it comes to acceptability in neutral contexts, the study that we ran has a broader reach and points to novel directions of inquiry. An intriguing result is that expressives appear to introduce contextual constraints not only when they occur in referential phrases such as 'quello stronzo'/'that jerk', which are the primary focus of the literature on expressives, but also when they are predicated of a subject, as in 'Bea è stronza'/'Bea is a jerk'. We see that the difference in acceptability between satisfying and neutral contexts in the Pred-EXP 
condition is significantly greater than it is in the Pred-CON condition. This suggests that 'jerk', even in the predicative form, imposes certain constraints on the context. ${ }^{14}$ In a context where people do not know whether Bea is Piedmontese, and a speaker says 'Bea is Piedmontese', interlocutors tend to find what the speaker says significantly more acceptable than in a similar context in which a speaker says 'Bea is a jerk' when interlocutors do not know whether Bea deserves a negative evaluation, or whether the speaker holds her in low opinion. We will return to this discrepancy in Study 2. For the time being, notice that, although participants might have associated positive or negative stereotypes with controllers such as 'Piedmontese' or 'sporty', results reflect that participants still rated the utterances featuring the expressive as significantly less acceptable in neutral contexts.

Yet another noteworthy result observed in our study is that in both conditions that involve the demonstrative construction 'that-' (viz. 'that jerk Bea' and 'that Piedmontese Bea'), we see that the rates of acceptability are significantly downgraded in the neutral condition in comparison to the satisfying condition. This may be due to the fact that the demonstrative construction requires something like presupposition accommodation, and requires speakers to perform some extra work. Now, if we pair this observation with the previous one, namely that 'jerk' is less acceptable in comparison to controllers even in the predicative position, it is tempting to conclude that when it comes to the complex demonstrative 'that jerk Bea', both the expressive item 'jerk' and the demonstrative construction itself must play some role in determining the contextual constraints imposed by the entire expression.

Relatedly, we also observe a difference in the acceptability of the controller items between the predicative and the demonstrative conditions in neutral contexts. In a context where people do not know whether Bea is Piedmontese, an utterance like 'That Piedmontese Bea has finished' is significantly less acceptable than 'Bea is Piedmontese'. There are at least two possible explanations: (i) the demonstrative construction may require presupposition accommodation, and this extra effort may be responsible for the decrease in acceptability; and (ii) since the use of a proper name inside a complex demonstrative is pragmatically marked, expressions such as 'that Piedmontese Bea' may trigger a derogatory interpretation. It may be, of course, that both phenomena are partly responsible for the results observed; but we must leave a further investigation of this issue for future research.

\section{Study 2}

Terms like 'stronzo' are expressives; moreover, just like many other swear words, they are taboo terms banned from what is considered socially acceptable language, and, in addition, they express a highly negative content. We may wonder which of these various features is responsible for the contextual constraints imposed by 'stronzo'.

One interesting result of Study 1, as already noted, is that the low acceptability of expressives in neutral contexts cannot be solely due to a taboo-effect that is sometimes imputed to the use of swear words, given that '(quello) stronzo' is perfectly acceptable in satisfying contexts. The contextual constraints imposed by '(quello) stronzo' cannot solely

\footnotetext{
${ }^{14}$ By suggesting that the expressive term 'jerk' in the predicative form may impose contextual constraints, we are by no means claiming that 'jerk', used as a predicate, triggers projective content. What we observe, rather, is that the availability of the relevant contextual information (viz. that someone is - or deserves to be - held in low opinion) has an impact on the acceptability of expressives to a much greater extent than in the case of nonexpressives, regardless of whether they are in the predicative or referential position.
} 
depend, then, on 'stronzo' being a taboo term.

However, the question arises whether the low(er) acceptability of Pred-EXP over Pred$\mathrm{CON}$ is due to the fact that, in general, it is less acceptable to say bad things about people, or rather, to the use of the expressive 'jerk'. One may raise the following worry: Study 1 does not rule out the possibility that any locution conveying negative properties might impose the contextual constraints that 'jerk' imposes. In order to address this worry, we ran a follow-up study, in which we compare sentences featuring negative expressive terms with sentences featuring negative non-expressive terms.

The follow-up study addresses the worry according to which the contextual constraints imposed by expressives may be entirely due to the fact that the speaker is saying something bad about the target, rather than having to do with the semantics and pragmatics of expressive terms per se. The worry will be ruled out if negative non-expressive terms such as 'nasty' receive higher average rates of acceptability in comparison to expressives like 'jerk'. ${ }^{15}$ As we are about to see, this is indeed what our Study 2 establishes.

\subsection{Methods}

\section{Participants}

103 participants took part to the study [Mean age= 26.47; SD $=11.38 ; 44 \mathrm{mls} ; 59 \mathrm{fmls}$ ]. Participants were all native Italian speakers. The experiment was administered online. Informed consent was obtained from every participant.

\section{Stimuli and Procedure}

We created 20 written vignettes in Italian. We included 8 target vignettes (randomly presented) and 12 fillers. In each target vignette, participants were presented a story. Each story consisted of a context scenario composed by three sentences followed by a target sentence. As in Study 1, the context scenarios describe a circumstance that introduces a conversation between two individuals speaking about a third person. The target sentence consists of an utterance of one of the two interlocutors concerning the third person. Target sentences were of two kinds, generating two experimental conditions: they had the very same structure, the only difference being that either they contained the expressive term 'stronzo' (.'jerk') (EXP) or else, they contained a non-expressive term that expresses a negative property (NEG). These expressions included: 'antipatico' ('nasty'), 'falsa' ('insincere'), 'cattivo' ('mean'), 'maleducata' (rude), 'sleale' ('disloyal'), 'odiosa' ('hateful'), 'insopportabile' ('unbearable'), 'scontrosa' ('grouchy'). Both NEG and EXP occurred in the predicative position, as in 'Marco is a jerk' or 'Marco is nasty'. See an example in Table 1.

\begin{tabular}{|l|l|l|}
\hline Condition & Context Sentence & Target Sentence \\
\hline
\end{tabular}

\footnotetext{
15 As previously noted, some authors, like Potts (2005), are inclined to include terms such as 'nasty' among expressives. Beside the problems of assimilating expressives and evaluative adjectives that we have already mentioned (see Berškytė and Stevens 2019), our study may be seen as revealing yet further disparities between the two classes of expressions.
} 


\begin{tabular}{|l|l|l|}
\hline EXP & $\begin{array}{l}\text { Sara e Luca sono a una festa di laurea. Il } \\
\text { festeggiato ha invitato anche Marco. } \\
\text { Quando Marco arriva alla festa, Luca dice a } \\
\text { Sara: }\end{array}$ & $\begin{array}{l}\text { Marco è stronzo } \\
\text { [Marco is a jerk }]\end{array}$ \\
\hline NEG & $\begin{array}{l}\text { [Sara and Luca are at a graduation party. } \\
\text { The host has invited Marco as well. } \\
\text { When Marco arrives, Luca tells Sara: }\end{array}$ & $\begin{array}{l}\text { Marco è antipatico } \\
\text { [Marco is nasty] }\end{array}$ \\
\hline
\end{tabular}

Tab 1. Example of a target vignette composed of a context scenario and the target sentence in conditions EXP and NEG.

Fillers had the same structure, except for the target sentence, which was something like 'Marco si sposa' ('Marco is getting married').

The context scenarios provided no information supporting the use of either the expressive term or the negative term, generating in this way a neutral context. This experimental manipulation resulted in a within-subject design where two experimental conditions were considered: EXP vs. NEG, that is, conditions featuring a negative expressive ('jerk') vs. a non-expressive negative term ('nasty'). As in Study 1, the procedure consisted in reading the context scenarios and in rating the target sentence on a 5-point Likert scale (1 unacceptable /5 completely acceptable).

\subsection{Results}

We analyzed whether there were any differences in the participants' response ratings to Expressives and Negatives. The mean rate for Expressives was 2,14(0,90). The mean rate for Negatives was 3.83(0,95). The non-parametric Wilcoxon Rank-Sum Test statistics revealed that this difference is highly significant $(\mathrm{W}=57983.5 ; \mathrm{p}<0.0001)$.

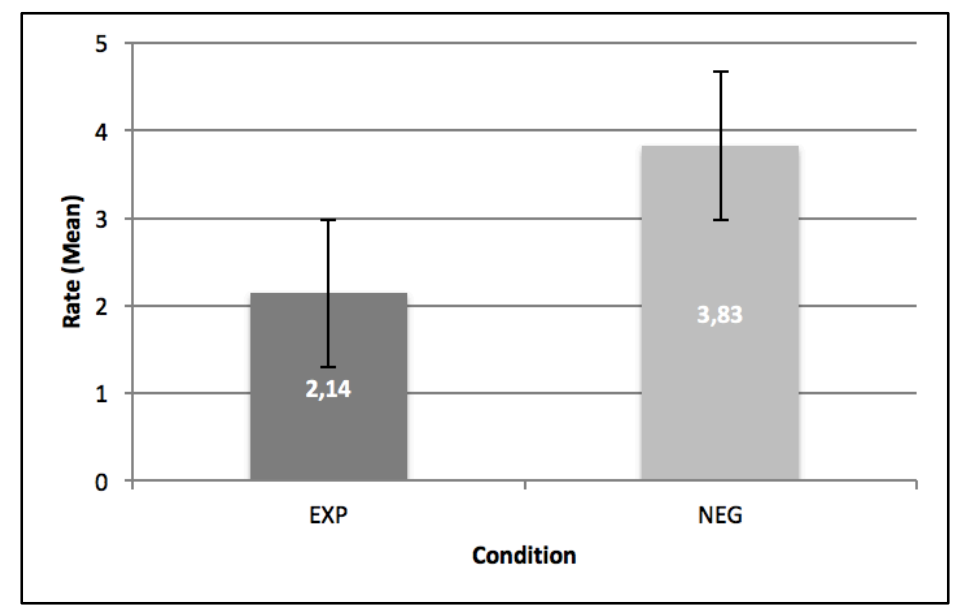

Fig 3. Mean rates to the sentences featuring the expressive (EXP) vs. the sentences featuring non-expressive negative terms (NEG) in neutral contexts (NEU). 


\subsection{Discussion}

The follow-up study rules out the worry that the contextual constraints imposed by 'stronzo' are the effect of a more general phenomenon, a hypothesis according to which it is in general unacceptable to say something negative about a subject without there being any supporting reason. As we see, to say something negative about the target in a neutral context is significantly more acceptable with a non-expressive negative term (e.g. 'Marco is nasty') than with an expressive (e.g. 'Marco is a jerk'). ${ }^{16}$

\section{Conclusion and prospects for future research}

Our study suggests that, pace Potts (2005), Schlenker (2007) and Tonhauser et al. (2013), expressives like 'that jerk' do impose certain contextual constraints. For their use to be acceptable, the associated projective content must be entailed by the context. This may require a revision of the mainstream view of expressives, and it surely encourages more empirical studies on the matter. ${ }^{17}$

In addition to this finding, our study sheds new light on several related questions. First, the results of Study 1 rule out the possibility that the contextual constraints imposed by 'jerk' and 'that jerk' are brought about by a taboo effect, given that '(quello) stronzo' is judged to be perfectly acceptable in satisfying contexts. Second, the results of Study 2 rule out the hypothesis that 'jerk' and 'that jerk' impose the contextual constraints they impose simply because they are terms that express something negative about the target. Rather, the constraints imposed by expressives appear to be tightly connected with their belonging to the lexical category of expressive terms.

Last but not least, we have underscored the importance of distinguishing between complex demonstratives featuring expressives (such as 'that jerk') and expressives in the predicative position (such as 'is a jerk'). Most existing accounts of expressives, including Kaplan (1999), Kratzer (1999), Macià (2002, 2011), Potts (2005, 2007), Tonhauser et al. (2013), are, in the end, accounts of expressives qua constituents of complex demonstratives. Once the distinction is made explicit, one can start addressing the question as to what determines the specific properties of complex demonstratives like 'that jerk', whether the expressive term by itself, or the demonstrative construction, or both. Further work is needed to look deeper into this issue, but our study already suggests that both the expressive term and the demonstrative construction must play a role in determining the behavior of complex expressives such as 'that jerk'.

\footnotetext{
16 One may object that the difference in average rates between EXP and NEG does not show that the effects brought about by EXP depend on its expressive nature: it may be the case that any negative term shows this effect (that of being unacceptable in neutral context and acceptable in satisfying ones), and that, since 'stronzo' is just more negative than the average of the others taken together, it only looks like 'stronzo' has a special behavior. In order to rule out this worry, we ran an analysis of the data that revealed that the acceptability of 'stronzo' is significantly lower than any other negative term taken alone. This means that none of the negative terms we tested behaves like 'stronzo'.

17 There have been empirical studies on expressives, in particular Harris and Potts (2009) and Kaiser (2015), but what they have tested is the availability of non-speaker-oriented uses of expressives. This topic, however important, remains somewhat orthogonal to the issues that we have tried to address.
} 


\section{References}

Amaral, Patricia, Craige Roberts, and Allyn Smith. 2007. "Review of The Logic of

Conventional Implicatures by Chris Potts." Linguistics and Philosophy 30, 707-749.

Anderson, Luvell, Haslanger, Sally and Langton, Rae (2012), Language and Race, in Fara,

Delia and Russell, Gillian (eds.), Routledge Companion to the Philosophy of Language,

London, Routledge, 753-767.

Ashwell, Lauren (2016), Gendered slurs, Social Theory and Practice, 42.2, 228-239.

Abbott, Barbara (2000), Presuppositions as nonassertions, Journal of Pragmatics, 32 (10), 1419-1437. doi:10.1016/S0378-2166(99)00108-3.

Abusch, Dorit (2002), Lexical Alternatives as a Source of Pragmatic Presupposition, Proceedings of Semantics and Linguistic Theory (SALT), 13, 1-19.

Abusch, Dorit (2010), Presupposition Triggering from Alternatives, Journal of Semantics, 27 , $37-80$.

Anderson, Luvell and Lepore, Ernie (2013a), Slurring Words, Noûs, 47 (1), 25-48.

Anderson, Luvell and Lepore, Ernie (2013b), What Did You Call Me? Slurs as Prohibited Words, Analytic Philosophy 54, 3, 350-63.

Berškyte, Justina, and Graham Stevens (2019), Semantic Relativism, Expressives, and Derogatory Epithets, Inquiry, 1-21.

Bolinger, Renée (2017), The pragmatics of Slurs, Noûs, 51 (3), 439-462.

Camp, Elisabeth (2013), Slurring Perspectives, Analytic Philosophy, 54 (3), 330-349.

Camp, Elisabeth (2018), A Dual Act Analysis of Slur, in Sosa, David (ed), Bad Words: Philosophical Perspectives on Slurs, Oxford: OUP.

Cepollaro, Bianca (forthcoming), Slurs and Thick Terms: When Language Encodes Values, Rowman \& Littlefield.

Cepollaro, Bianca, and Isidora Stojanovic. 2016. "Hybrid Evaluatives.” Grazer

Philosophische Studien 93, no. 3: 458-88.

Chierchia, Gennaro and McConnell-Ginet, Sally (1990), Meaning and Grammar, Cambridge (MA), MIT Press.

Harris, Jesse and Potts, Christopher (2009), Perspective-shifting with Appositives and Expressives, Linguistics \& Philosophy, 32, 523-552

Hom, Christopher (2008), The Semantics of Racial Epithets, The Journal of Philosophy, 105 (8), 416-440.

Jeshion, Robin (2013), Expressivism and the Offensiveness of Slurs, Philosophical Perspectives, 27 (1), 231-259.

Jeshion, Robin (2018), Slurs, Dehumanization, and the Expression of Contempt, in Sosa, David, Bad Words: Philosophical Perspectives on Slurs, Oxford: OUP.

Kaiser, Elsi (2015), Perspective-shifting and Free Indirect Discourse, Proceedings of Semantics and Linguistic Theory (SALT), 25, 346-372.

Kaplan, David (1999), 'The Meaning of Ouch and Oops (Explorations in the Theory of Meaning as Use), manuscript.

Kratzer, Angelika (1999), Beyond Ouch and Oops: How Descriptive and Expressive Meaning Interact. A comment on David Kaplan's paper, Cornell Conference on Theories of Context Dependency, 1999. 
Lasersohn, Peter (2007), Expressives, Perspective and Presupposition, Theoretical Linguistics, 33(2), 223-230.

Lasersohn, Peter (2017), Subjectivity and Perspective in Truth-Theoretic Semantics, Oxford Studies in Semantics and Pragmatics (vol. 8), Oxford, Oxford University Press.

Lewis, David (1979), Scorekeeping in a Language Game, Journal of Philosophical Logic, 8 (1): 339-359.

Macià, Josep (2002), Presuposición y Significado Expressivo, Theoria: Revista de Teoria, Historia y Fundamentos de la Ciencia, 3 (45), 499-513.

Macià, Josep (2011), A Defense of the Presuppositional View of Expressive Meaning, Handout for ECAP-7, Milan.

McCready, E. (2010), Varieties of Conventional Implicature, Semantics and Pragmatics, 3, 8: 1-8: 57.

Nunberg, Geoffrey (2018), The Social Life of Slurs, in Fogal, Daniel, Harris, Daniel and Moss, Matt (eds.), New Work on Speech Act, Oxford, Oxford University Press.

Saka, Paul (2007), How to Think About Meaning, Springer.

Schlenker, Philippe (2007), Expressive Presuppositions, Theoretical Linguistics, 33 (2), 237-245.

Simons, Mandy (2001), On the Conversational Basis of Some Presuppositions, Proceedings of Semantics and Linguistic Theory (SALT), 11, 431-448.

Simons, Mandy, Tonhauser, Judith, Beaver, David, and Roberts, Craige (2011), What Projects and Why, Proceedings of Semantics and Linguistic Theory (SALT), 22, 309-327.

Soria Ruiz, Andrés and Stojanovic, Isidora (2019). On Linguistic Evidence for Expressivism. Royal Institute of Philosophy Supplement 86:155-180.

Potts, Christopher (2005), The Logic of Conventional Implicatures. Oxford: OUP.

Potts, Christopher (2007), The Expressive Dimension, Theoretical Linguistics, 33, 165-197.

Tonhauser, Judith, Beaver, David, Roberts, Craige and Simons, Mandy (2013), Toward a Taxonomy of Projective Content, Language, 89 (1), 66-109. 